\title{
The effect of PS-341 on pulmonary vascular remodeling in high blood flow-induced pulmonary hypertension
}

\author{
XUE ZHANG $^{1 *}$, ZONG-SHUAI WANG $^{1 *}$, YUN LUAN $^{2}$, MEI LIN $^{1}$, XIAO-BO ZHU ${ }^{1}$, \\ $\mathrm{YU} \mathrm{MA}^{1}$, ZHAO-HUA ZHANG ${ }^{1}$ and YI-BIAO WANG ${ }^{1}$ \\ ${ }^{1}$ Department of Pediatrics, ${ }^{2}$ Central Research Laboratory, \\ The Second Hospital of Shandong University, Jinan, Shandong 250033, P.R. China
}

Received July 27, 2013; Accepted October 25, 2013

DOI: $10.3892 /$ ijmm.2013.1562

\begin{abstract}
The aim of the present study was to investigate the effects of PS-341 on vascular remodeling in an experimental rat model of high blood flow-induced pulmonary arterial hypertension (PAH), as well as to elucidate its mechanisms of action. We established the PAH model by a surgical method that implanted a left-to-right shunt. Three days post-surgery, the animals were randomly assigned to 3 groups ( $n=15$ in each group): sham-operated (control), shunt (model) and PS-341 (treated) groups. Eight weeks post-surgery, hemodynamic parameters were significantly improved in the PS-341 group compared with the shunt group $(\mathrm{P}<0.05)$. Immunohistochemical analysis indicated that the expression levels of ubiquitin and nuclear factor- $\kappa \mathrm{B}(\mathrm{NF}-\kappa \mathrm{B})$ p65 were significantly higher in the shunt group compared with the sham-operated group $(\mathrm{P}<0.05)$. Semi-quantitative western blot analysis further confirmed that the levels of ubiquitin and $\mathrm{NF}-\kappa \mathrm{B}$ p65 were decreased, while those of I $\mathrm{B}-\alpha$ (an inhibitor of $\mathrm{NF}-\kappa \mathrm{B}$ ) were significantly increased in the PS-341 group compared with the shunt group $(\mathrm{P}<0.05)$. In conclusion, PS-341 attenuates high blood flow-induced pulmonary artery remodeling in rats via inhibition of the NF- $\mathrm{B}$ pathway.
\end{abstract}

\section{Introduction}

Pulmonary arterial hypertension (PAH) is a common complication of congenital heart disease caused by a left-to-right shunt. It is a condition characterized by an increase in pulmonary vascular resistance and remodeling, structural remodeling of the heart, right heart dysfunction and widespread loss of pulmonary microvasculature, leading to right-heart failure and premature decease (1-7). In recent years, despite significant progress being made in the development of drugs for the tret-

Correspondence to: Professor Yi-Biao Wang, Department of Pediatrics, The Second Hospital of Shandong University, 247 North Park Avenue, Jinan, Shandong 250033, P.R. China

E-mail:wangyibiao@sdu.edu.cn

${ }^{*}$ Contributed equally

Key words: PS-341, vascular remodeling, ubiquitin, nuclear factor- $\kappa \mathrm{B}$ ment of PAH, the effects of currently used drugs are not ideal, while the mechanisms causing PAH formation have not yet been fully elucidated. Vascular structural remodeling is considered the key process in the pathology of hypoxic pulmonary hypertension (8). Pulmonary vascular structural remodeling is mainly caused by high pulmonary blood flow (9), which leads to neointimal formation and hyperplasia of the medial vascular wall, resulting from an imbalance between proliferation and apoptosis in pulmonary vascular smooth muscle cells favoring proliferation (VSMCs) $(10,11)$.

The cytoplasmic activity of the transcription factor nuclear factor- $\kappa \mathrm{B}(\mathrm{NF}-\kappa \mathrm{B})$ has been shown to be regulated through its association with the I $\mathrm{B}$ - $\alpha$ protein, itself regulated by the ubiquitin (Ub)-proteasome system (UPS) $(12,13)$. Previous studies have demonstrated that the NF- $\mathrm{BB}$ pathway plays an important role in pulmonary vascular remodeling $(14,15)$. However, studies of the underlying mechanisms of vascular remodeling via the NF- $\mathrm{KB}$ pathway remain are limited.

The proteasome inhibitor, PS-341 (FDA approved drug: Bortezomib/Velcade), has the potential to inhibit NF- $\kappa$ B activation by reducing the degradation of I $\kappa \mathrm{B}-\alpha$. In the present study, we established a high blood flow-induced pulmonary hypertension model to study vascular remodeling, using a surgical aorto-caval shunt (ACS) method. We hypothesized that low doses of PS-341 may prevent pulmonary vascular remodeling through the inhibition of the $\mathrm{NF}-\kappa \mathrm{B}$ signaling pathway, by downregulating the UPS.

\section{Materials and methods}

Animals and reagents. Male Wistar rats, weighing 140-200 g, were purchased from the Animal Experimental Center of Shandong University, Jinan, China. All experimental procedures were approved by the Institutional Animal Ethics Committee of Shandong University.

Six-week-old rats $(n=45)$ were randomly divided into 3 groups ( $n=15$ in each group): the sham-operated, shunt and PS-341 groups. PS-341 was kindly provided by Karolinska Institute, Stockholm, Sweden and the dose used was in accordance with that used in previous studies $(13,16,17)$.

Animal model preparation. The animal model of ACS was established using a previously described surgical method (18). 
Briefly, the animals were anesthetized with an injection of $0.25 \%$ pentobarbital sodium $(40 \mathrm{mg} / \mathrm{kg})$. With the abdominal aorta and inferior vena cava fully exposed, a bulldog vascular clamp was placed across the aorta caudal to the left renal artery. The aorta was punctured using an 18-gauge disposable needle, which was subsequently withdrawn. A silk thread was then used to stitch the puncture of the abdominal wall. Swelling of the vena cava and mixing of arterial and venous blood confirmed the implantation of the shunt. Three days post-surgery, the rats that survived were randomly divided into 3 groups ( $n=15$ in each group): the sham-operated, shunt and PS-341 groups. The sham-operated group was subjected to a sham operation with the same procedure apart from the shunt implantation. The PS-341 group received an intraperitoneal injection of PS-341 $(50 \mu \mathrm{g} / \mathrm{kg})$ for 8 weeks following shunt implantation, while the shunt group received the same dose of saline instead of PS-341. Heparin $(0.5 \mathrm{mg} / \mathrm{kg})$ was injected intra-abdominally $6 \mathrm{~h}$ post-surgery and penicillin $(20 \mathrm{mg} / \mathrm{kg})$ was injected during the following 3 days.

Measurement of pulmonary arterial pressure. Eight weeks following the establishment of the model, the hemodynamic parameters of the animals were measured as previously described (19). Briefly, a 3F-microtip transducer catheter (Millar Instruments Inc., Houston, TX, USA) connected to a data acquisition system (Biopac Systems, Inc. Goleta, CA, USA) was inserted via the right jugular vein into the right ventricle (RV) to obtain baseline measurements of heart rate (HR), central venous pressure (CVP) and right ventricular systolic pressure (RVSP).

Preparation of heart and lung tissues. Following the measurement of hemodynamic parameters, the rats were sacrificed, and the weights of the RV, the left ventricle (LV) and the ventricular septum (SEP) were recorded. The ratio of the right ventricular free wall weight to the sum of left ventricular plus septal weight $(\mathrm{RV} / \mathrm{LV}+\mathrm{S})$ was determined to evaluate the extent of hypertrophy in the RV. Lung tissue samples of a few animals were quickly harvested and embedded in optical cutting temperature medium (OCT; Sigma-Aldrich, St. Louis, MO, USA), frozen in liquid nitrogen and stored at $-80^{\circ} \mathrm{C}$. These samples were subsequently used for western blot analysis. An additional lung tissue sample was fixed in a $10 \%$ formaldehyde buffer solution in situ using a tracheal cannula, and was embedded in paraffin. The tissue sections were then cut into $5-\mu \mathrm{m}$-thick slices and were stained with hematoxylin and eosin (H\&E) and Masson's trichrome dye. The morphological alterations of the pulmonary arterial wall were observed under an optical microscope as previously described (20). The percentages of medial wall thickness (WT\%) and medial wall areas (WA\%) with an external diameter (ED) of $15-50 \mu \mathrm{m}$ were calculated in at least 10 arteries in each group to evaluate vascular remodeling. These studies were performed by 2 examiners blinded to treatment allocation.

Immunohistochemical analysis. The lung tissue sections were blocked with $2 \%$ goat serum for $30 \mathrm{~min}$ and then washed with Public Broadcasting Service (PBS) working fluid, cut into $5-\mu \mathrm{m}$-thick slices and incubated with primary antibodies following fixation in acetone for $10 \mathrm{~min}$ at $4^{\circ} \mathrm{C}$. The protein content of the pulmonary arterial smooth muscle cells (PASMCs) was semi-quantitatively assessed by immunohistochemistry, carried out with monoclonal mouse anti-ubiquitin antibody (1:200) and rabbit anti-NF- $\kappa$ B p65 antibody (1:100; Abcam, Cambridge, UK) following the manufacturer's recommendations. Subsequently, the 3,3'-diaminobenzidine (DAB) dye was added to visualize the antibodies, and following washing of the tissue sections with phosphate-buffered saline (PBS) solution, the sections were observed and photographed under a microscope.

Western blot analysis. The lung tissue samples were homogenized in liquid nitrogen and equal amounts of protein were denatured and separated by sodium dodecyl sulfate-polyacrylamide gel electrophoresis (SDS-PAGE). Protein concentrations were semi-quantitatively assessed using the BCA Protein Assay kit (Santa Cruz Biotechnology, Inc., Santa Cruz, CA, USA). Proteins $(50 \mu \mathrm{g})$, loaded onto a $10 \%$ SDS-polyacrylamide gel and electroblotted onto a nitrocellulose membrane. The membrane was blocked for $16 \mathrm{~h}$ at $4^{\circ} \mathrm{C}$ in blocking buffer containing 5\% skim milk powder in TBST $[20 \mathrm{mM}$ Tris $\mathrm{HCl}$ (pH 7.4), $150 \mathrm{mM} \mathrm{NaCl}$ and $0.1 \%$ Tween-20] and incubated with anti-ubiquitin $(1: 1,000)$, anti NF- $\mathrm{B}$ p65 $(1: 2,000)$ and antiIкB- $\alpha(1: 1,000)$ antibodies (all from Santa Cruz Biotechnology, Inc.) and washed with Tris-buffered saline with TBST. The goat anti-rabbit IgG (Boshide Inc., Shanghai, China) was incubated at $37^{\circ} \mathrm{C}$ for $1 \mathrm{~h}$ as the secondary antibody. Immunoreactions were visualized using an electrochemiluminescence (ECL) system according to the manufacturer's instructions (Thermo Fisher Scientific Co., Ltd., Shanghai, China).

Statistical analysis. The data are presented as the means \pm SD. A one-way ANOVA was performed for the statistical comparison of differences between groups, using SPSS 16.0 software. A P-value $<0.05$ was considered to indicate a statistically significant difference.

\section{Results}

Mortality of the animals. No mortality was observed in the sham-operated group, while 2 rats in the shunt group died from acute pulmonary edema within the first week post-surgery and were replaced. In total, 45 rats in each group were available for further analyses.

Evaluation of hemodynamic parameters. There was no significant difference in the initial HR, CVP and RVSP values among the 3 groups. Eight weeks after the establishment of the ACS model, RVSP was significantly elevated in the shunt group compared with the sham-operated group $(\mathrm{P}<0.05)$, and was significantly lower compared with the PS-341 group $(\mathrm{P}<0.05)$. The ratio of $\mathrm{RV} /(\mathrm{LV}+\mathrm{S})$ was significantly higher in the shunt compared with the sham-operated group $(\mathrm{P}<0.05)$, and was significantly lower in the PS-341 group compared with the shunt group $(\mathrm{P}<0.05)$. These results indicated that severe pulmonary hypertension and right ventricular hypertrophy occurred; thus our model of high blood flow-induced PAH was successfully established.

Evaluation of changes in the pulmonary artery wall structure. Eight weeks post-surgery, H\&E staining demonstrated a significant thickening of the intima and stenosis of muscular arteries in the shunt compared with the sham-operated group. The 

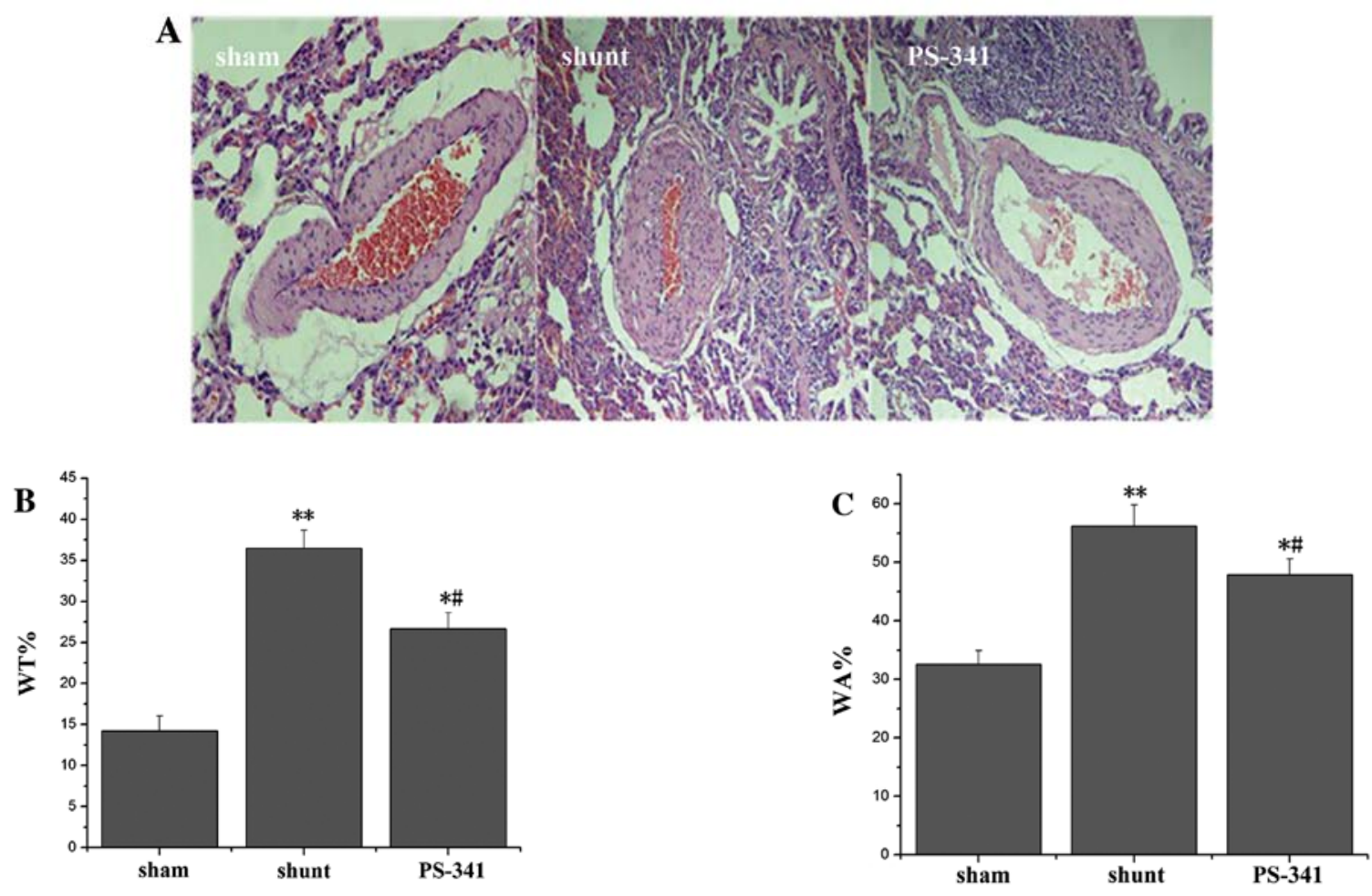

Figure 1. (A) Haematoxylin and eosin (H\&E) staining demonstrated thickening of the intima in the shunt group compared with the sham-operated group 8 weeks following the establishment of the aorto-caval shunt model. Upon treatment with PS-341, a significant improvement was observed compared with the shunt group (magnification, x100). (B) Comparison of the percentages of medial wall thickness (WT\%) and of (C) medial wall area (WA\%) of muscular arteries with an external diameter of 50-150 $\mu \mathrm{m}$ among the 3 groups: both values were significantly increased in the shunt compared with the sham-operated group, and significantly decreased in the PS-341 compared with the shunt group. The data are presented as the means $\pm \mathrm{SD}(\mathrm{n}=15)$. ${ }^{*} \mathrm{P}<0.05$ and ${ }^{* *} \mathrm{P}<0.01$ compared with the sham-operated group; ${ }^{\#} \mathrm{P}<0.05$ compared with the shunt group.

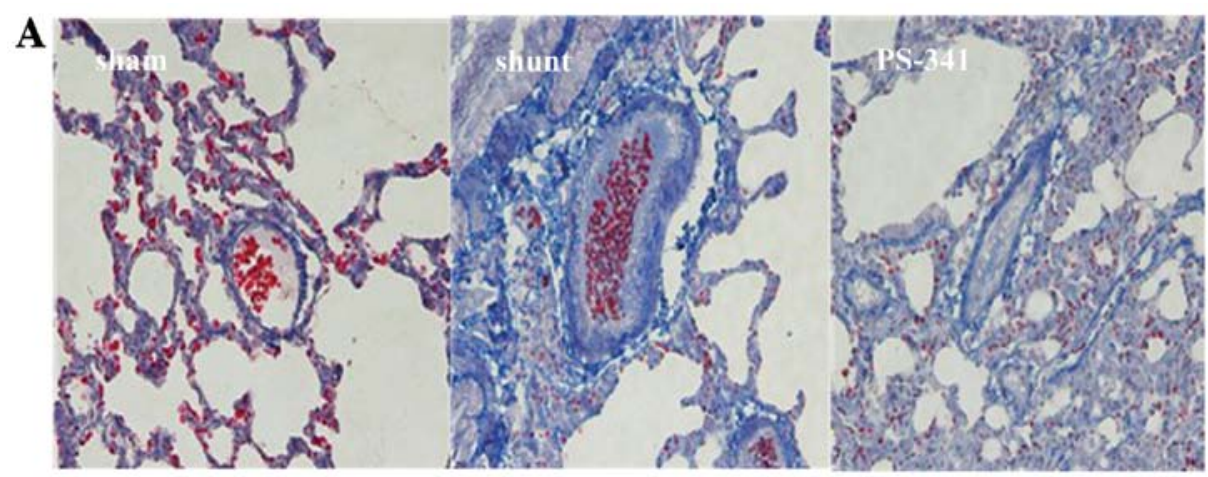

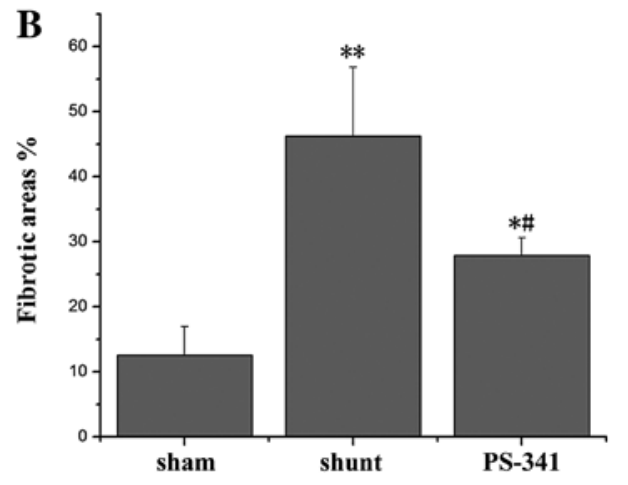

WT\% and WA\% of muscular arteries with an ED of 15-50 $\mu \mathrm{m}$ was significantly decreased in the PS-341 group compared with the shunt group $(\mathrm{P}<0.05)$ (Fig. 1). Masson's trichrome staining (Fig. 2A) revealed that the vessel wall was obscured, the lumen
Figure 2. (A) Staining with Masson's trichrome dye revealed that the vessel wall was obscured, the lumen size was reduced, and there was a notable increase in collagen and in interstitial fibrosis in the shunt group as compared with the sham group. Following treatment with PS-341, the above changes were reversed (magnification, x100). (B) Comparison of the percentage of fibrotic areas in the muscular arteries among the 3 groups: the percentage of the fibrotic areas (fibrotic areas \%) was significantly increased in the shunt compared with the sham-operated group, and significantly decreased in the PS-341 compared with the shunt group. The data are presented as the means $\pm S D(n=15) .{ }^{*} \mathrm{P}<0.05$ and ${ }^{* *} \mathrm{P}<0.01$ compared with the sham group; ${ }^{\text {"}} \mathrm{P}<0.05$ compared with the shunt group.

size was reduced, and the level of collagen was increased, while a significant increase in the number of interstitial fibrotic areas was observed in the shunt group compared with the shamoperated group $(\mathrm{P}<0.01)$ (Fig. 2B). Following treatment with 

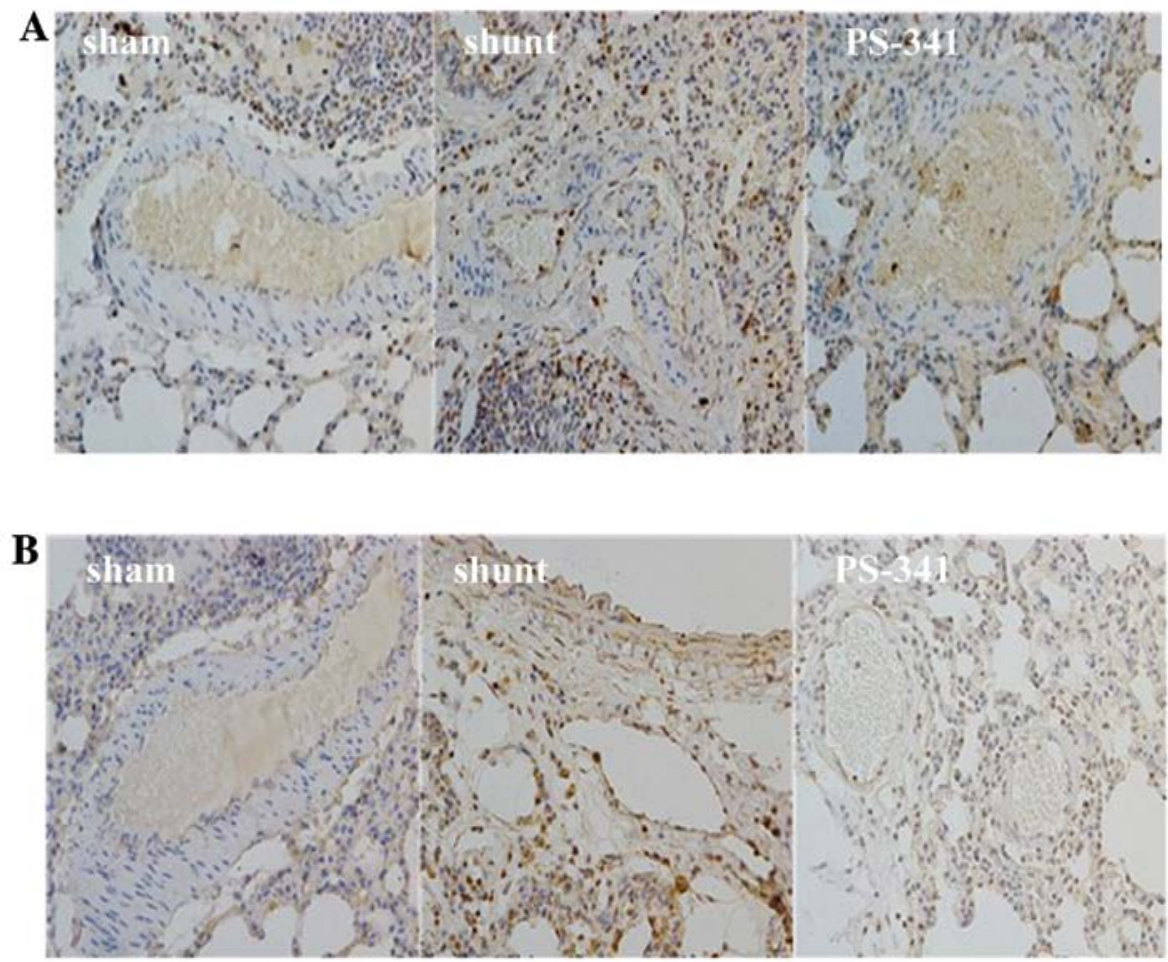

Figure 3. (A) Ubiquitin and (B) nuclear factor (NF)- $\mathrm{kB}$ p65 detected by immunohistochemistry and immunofluorescence in pulmonary artery smooth muscle cells. The detected levels of ubiquitin and NF-kB p65 appeared higher in the shunt group as compared with the sham-operated group, and lower in the PS-341 group (magnification, x200).
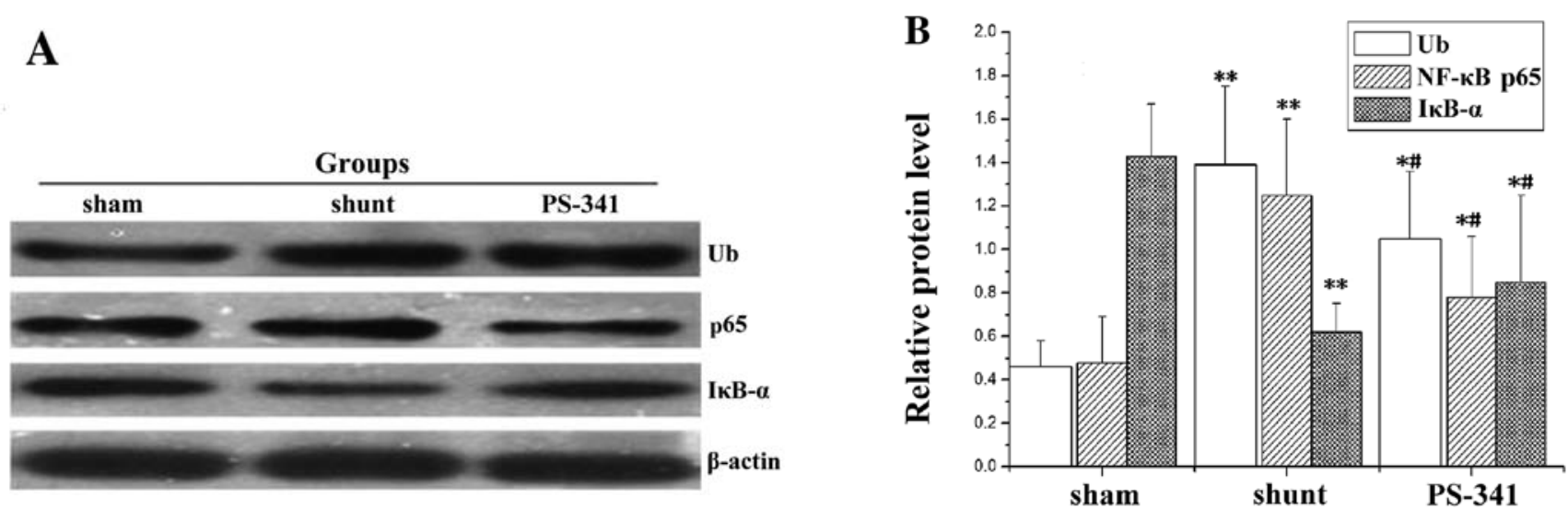

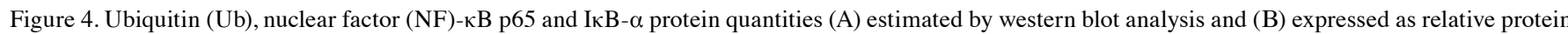
levels (normalized to $\beta$-actin). The protein concentrations of $\mathrm{Ub}$ and NF- $\mathrm{kB}$ p65 in the lung tissue samples of the shunt group were significantly increased and the levels of IкB- $\alpha$ were significantly reduced compared with the sham-operated group. Following treatment with PS-341 for 8 weeks, the protein concentra-

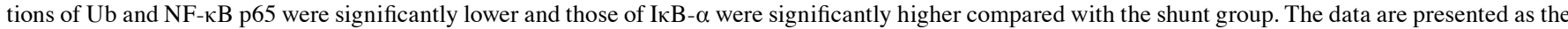
means $\pm \mathrm{SD}(\mathrm{n}=15) .{ }^{*} \mathrm{P}<0.05$ and ${ }^{* *} \mathrm{P}<0.01$ compared with the sham-operated group; ${ }^{*} \mathrm{P}<0.05$ compared with the shunt group.

PS-341, the above changes were significantly reversed. These results also indicated that the vascular remodeling model was successful established.

Ubiquitin and $N F-\kappa B$ p65 expression detected by immunohistochemistry. There were significant differences observed in the expression levels of ubiquitin and NF- $\mathrm{kB}$ p65 in the PASMCs in the 3 groups at 8 weeks post-surgery. Ubiquitin and NF- $\mathrm{KB}$ p65 were detected in significantly higher levels in the shunt compared with the sham-operated group $(\mathrm{P}<0.01)$, and in significantly lower levels in the PS-341 group $(\mathrm{P}<0.05)$ (Fig. 3).

Ubiquitin, $N F-\kappa B$ p 65 and $I \kappa B$ - $\alpha$ protein quantities estimated by western blot analysis. The protein concentrations of ubiquitin and NF-kB p65 in the lung tissue samples of the shunt group were significantly increased, while the levels of IкB- $\alpha$ were significantly reduced compared with the sham-operated group $(\mathrm{P}<0.01)($ Fig. 4). The protein concentrations of ubiquitin and NF- $\kappa B$ p65 were significantly lower $(\mathrm{P}<0.05)$ and those of 
I $\kappa \mathrm{B}-\alpha$ were significantly higher $(\mathrm{P}<0.05)$ compared with the shunt group following treatment with PS-341 for 8 weeks.

\section{Discussion}

Although a number of studies have addressed the role of the UPS in the primary VSMC phenotype and survival signaling and in ventricular remodeling $(14,15)$, its involvement in pulmonary vascular remodeling induced by high blood flow-induced PAH remains unclear and the underlying mechanisms have not yet been fully elucidated. To our knowledge, the present study is the first to demonstrate that 8 weeks following the intraperitoneal injection of PS-341, pulmonary vascular remodeling was considerably attenuated in a model of high blood flow-induced PAH. Following treatment with PS-341, we observed the following results: i) hemodynamic parameters were significantly improved; ii) the WT\% and WA\% (ED, 50-150 $\mu \mathrm{m})$, the fibrotic area and the $\mathrm{RV} /(\mathrm{LV}+\mathrm{S})$ weight ratio were significantly

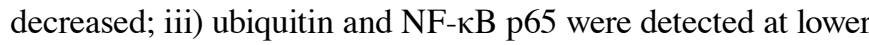
levels in the PASMCs; and iv) the protein concentrations of ubiquitin and $N F-\kappa B$ p 65 were significantly decreased; the levels of I $\kappa$ B- $\alpha$ (an NF- $\kappa$ B inhibitor) were significantly increased. These results suggested that the activation of the NF- $\mathrm{BB}$ pathway was significantly inhibited following treatment with PS-341.

UPS is an ATP-dependent multi-enzymatic process (21). It consists of an ubiquitin-conjugating system and the proteasome, and it is the main intracellular protein degradation pathway in eukaryotic cells $(22,23)$. Ubiquitin is an $8 \mathrm{kDa}$ protein of 76 amino-acids, expressed in all eukaryotic cells. The process of protein ubiquitination involves the covalent attachment of ubiquitin to a target protein, which serves as a signal for protein degradation by the proteasome (24). The degradation of the targeted protein is performed by the $26 \mathrm{~S}$ proteasome, which consists of a barrel-shaped proteolytic core complex (the $20 \mathrm{~S}$ proteasome) and a $19 \mathrm{~S}$ cap complex $(11,25)$. A previous study (26) demonstrated that the inhibition of cell cycle-controlling ubiquitin ligases or the proteasome can reduce VSMC proliferation and prevent the modulation of their synthetic phenotype. UPS can promote protein degradation underlying the transition from a contractile to a proliferative VSMC phenotype; thus, proteasome inhibition leads to a shift from a synthetic and proliferative phenotype to a contractile one (27,28). All the above studies have demonstrate that UPS has a critical effect on the phenotypic changes of VSMCs and underlies the transition towards the synthetic phenotype. $\mathrm{NF}-\kappa \mathrm{B}$ plays a key role in the process of vascular remodeling in a variety of physiological and pathophysiological states (13). The activity of NF- $\kappa \mathrm{B}$ is regulated in the cytoplasm through its association with the I $\kappa$ B- $\alpha$ protein, which is regulated by the UPS. The proteasome-mediated degradation of the inhibitor, I $\kappa \mathrm{B}-\alpha$, is required for $\mathrm{NF}-\kappa \mathrm{B}$ activation, with the phosphorylation of I $\mathrm{B}-\alpha$ promoting its ubiquitination and subsequent proteasomal degradation (29).

PAH occurs when most of the very small arteries in the lungs narrow in diameter (30), leading to increased pulmonary vascular resistance, functional and structural changes in the pulmonary vasculature, lung vascular remodeling, loss of the distal pulmonary vasculature (31), and RV dysfunction (32). A number of therapies has been proven useful for decreasing pulmonary arterial pressure and improving tolerance to exercise and life quality; however, an effective and long-lasting treatment for this disorder is still lacking $(33,34)$. The main pathological features of PAH are: remodeling of the pulmonary arteries, resulting from endothelial dysfunction and proliferation, smooth muscle hyperplasia and hypertrophy and expansion of the adventitial matrix. Studies have shown that endothelial dysfunction is a key feature and an early event in the pathogenesis of PAH $(33,35)$.

In the present study, we established a model of high blood flow-induced PAH by a surgical method that implanted a leftto-right shunt. Eight weeks post-surgery, RVSP and the ratio of $\mathrm{RV} /(\mathrm{LV}+\mathrm{S})$ were significantly higher; H\&E and Masson's staining illustrated that the intima thickened, the vessel wall was obscured, the lumen size was reduced, and the fibrotic areas were increased; the WT\% and WA\% of muscular arteries with an ED of 15-50 $\mu \mathrm{m}$ were significantly increased (Figs. 1 and 2). Following treatment with PS-341, the hemodynamic and morphometric parameters were improved. These results indicate that the PAH model was successfully established and that PS-341 can prevent PHA and can attenuate pulmonary vascular remodeling in high blood flow-induced PAH.

The proteasome inhibitor, PS-341, is currently the only FDA approved drug (Bortezomib/Velcade) with well characterized inhibitory effects on the activity of NF- $\kappa \mathrm{B}(36,37)$. In order to further examine the beneficial effects of PS-341 on vascular remodeling in $\mathrm{PAH}$, we performed immunohistochemical staining and western blot analysis to detect the levels of UPS-related proteins, such as ubiquitin, NF- $\kappa$ B p65 and I $\mathrm{B}-\alpha$. Our results revealed that the expression levels of ubiquitin and $\mathrm{NF}-\kappa \mathrm{B}$ p 65 were significantly reduced; the levels of I $\mathrm{B}-\alpha$ were significantly increased 8 weeks post-treatment with PS-341, as compared with the shunt group. These results indicated that the proteasome inhibitor, PS-341, inhibited UPS by downregulating the expression of $\mathrm{NF}-\kappa \mathrm{B}$ p 65 and preventing the degradation of IкB- $\alpha$. Other studies $(12,38,39)$ have demonstrated that a basal NF- $\kappa \mathrm{B}$ activity may serve to sustain the proliferation and survival of smooth muscle cell; treatment with the proteasome inhibitors, PS-341 or MG-132, has been shown to effectively and dose-dependently reduce neointimal formation in balloon-injured rat carotid arteries, which was associated with anti-proliferative, anti-inflammatory and pro-apoptotic effects mediated by the inhibition of tumor necrosis factor- $\alpha$-induced $\mathrm{NF}-\kappa \mathrm{B}$ activation. Our study demonstrates that treatment with PS-341 clearly suppresses pulmonary vascular remodeling through the inhibition of the NF- $\mathrm{B}$ signaling pathway.

In conclusion, our study demonstrates that the intraperitoneal injection of PS-341 for 8 weeks prevents pulmonary vascular remodeling in a model of high blood flow-induced $\mathrm{PAH}$ through the inhibition of the NF- $\kappa \mathrm{B}$ pathway.

\section{Acknowledgements}

This study was supported by the Key Technologies R\&DProgram of Shandong Province (2010GSF10234) and the Shandong Provincial Natural Science Foundation (ZR2011HM078).

\section{References}

1. Li B, Yang L, Shen J, Wang C and Jiang Z: The antiproliferative effect of sildenafil on pulmonary artery smooth muscle cells is mediated via upregulation of mitogen-activated protein kinase phosphatase-1 and degradation of extracellular signal-regulated kinase 1/2 phosphorylation. Anesth Analg 105:1034-1041,2007. 
2. Ohata Y, Ogata S, Nakanishi K, et al: Expression of P2X4R mRNA and protein in rats with hypobaric hypoxia-induced pulmonary hypertension. Circ J 75: 945-954, 2011.

3. Yildiz P: Molecular mechanisms of pulmonary hypertension. Clin Chim Acta 403: 9-16, 2009.

4. Can MM, Tanboğa IH, Demircan HC, et al: Enhanced hemostatic indices in patients with pulmonary arterial hypertension: an observational study. Thromb Res 126: 280-282, 2010.

5. Junbao D, Hui Y, Bing W, Jian L, Jianguang Q and Chaoshu T: Effect of L-arginine on collagen of high flow-induced pulmonary arterial remodeling. Circ J 69: 603-608, 2005.

6. Baber SR, Deng W, Master RG, et al: Intratracheal mesenchymal stem cell administration attenuates monocrotaline-induced pulmonary hypertension and endothelial dysfunction. Am J Physiol Heart Circ Physiol 292: H1120-H1128, 2007.

7. Zhao YD, Courtman DW, Ng DS, et al: Microvascular regeneration in established pulmonary hypertension by angiogenic gene transfer. Am J Respir Cell Mol Biol 35: 182-189, 2006.

8. Sun Y, Tian Y, Prabha M, et al: Effects of sulfur dioxide on hypoxic pulmonary vascular structural remodeling. Lab Invest 90: 68-82, 2010

9. Cuifen Z, Lijuan W, Li G, Wei X, Zhiyu W and Fuhai L: Changes and distributions of peptides derived from proadrenomedullin in left-to-right shunt pulmonary hypertension of rats. Circ J 72 : 476-481, 2008

10. McMurtry MS, Bonnet S, Wu X, et al: Dichloroacetate prevents and reverses pulmonary hypertension by inducing pulmonary artery smooth muscle cell apoptosis. Circ Res 95: 830-840, 2004

11. Li M, Dong X, Liu Y, Sun X, Li Z and He J: Inhibition of ubiquitin proteasome function suppresses proliferation of pulmonary artery smooth muscle cells. Naunyn Schmiedebergs Arch Pharmacol 384: 517-523, 2011.

12. Takami Y, Nakagami H, Morishita R, et al: Ubiquitin carboxylterminal hydrolase L1, a novel deubiquitinating enzyme in the vasculature, attenuates NF-kappaB activation. Arterioscler Thromb Vasc Biol 27: 2184-2190, 2007.

13. Ma Y, Chen B, Liu D, et al: MG132 treatment attenuates cardiac remodeling and dysfunction following aortic banding in rats via the NF- $\mathrm{kB} / \mathrm{TGF} \beta 1$ pathway. Biochem Pharmacol 81: 1228-1236, 2011.

14. Jin UH, Suh SJ, Chang HW, et al: Tanshinone IIA from Salvia miltiorrhiza BUNGE inhibits human aortic smooth muscle cell migration and MMP-9 activity through AKT signaling pathway. J Cell Biochem 104: 15-26, 2008.

15. Djordjevic T, Hess J, Herkert O, Görlach A and BelAiba RS Rac regulates thrombin-induced tissue factor expression in pulmonary artery smooth muscle cells involving the nuclear factor-kappaB pathway. Antioxid Redox Signal 6: 713-720, 2004.

16. Meiners S, Dreger H, Fechner M, et al: Suppression of cardiomyocyte hypertrophy by inhibition of the ubiquitin-proteasome system. Hypertension 51: 302-308, 2008.

17. Wrana JL, Attisano L, Wieser R, Ventura F and Massagué J: Mechanism of activation of the TGF-beta receptor. Nature 370 : 341-347, 1994

18. Li W, Jin HF, Liu D, et al: Hydrogen sulfide induces apoptosis of pulmonary artery smooth muscle cell in rats with pulmonary hypertension induced by high pulmonary blood flow. Chin Med J (Engl) 122: 3032-3038, 2009

19. Luan Y, Zhang ZH, Wei DE, et al: Implantation of mesenchyma stem cells improves right ventricular impairments caused by experimental pulmonary hypertension. Am J Med Sci 343 402-406, 2012.

20. Wang YY, Luan Y, Zhang X, et al:Proteasome inhibitor PS-341 attenuates flow-induced pulmonary arterial hypertension. Clin Exp Med: June 16, 2013 (Epub ahead of print).
21. Depre C, Wang Q, Yan L, et al: Activation of the cardiac proteasome during pressure overload promotes ventricular hypertrophy. Circulation 114: 1821-1818. 2006.

22. Naujokat $\mathrm{C}$ and Hoffmann S: Role and function of the $26 \mathrm{~S}$ proteasome in proliferation and apoptosis. Lab Invest 82: 965-980, 2002.

23. Doll D, Sarikas A, Krajcik R and Zolk O: Proteomic expression analysis of cardiomyocytes subjected to proteasome inhibition. Biochem Biophys Res Commun 353: 436-442, 2007.

24. Voutsadakis IA: Ubiquitination and the Ubiquitin-Proteasome System as regulators of transcription and transcription factorsin epithelial mesenchymal transition of cancer. Tumour Biol 33: 897-910, 2012.

25. Moore BS, Eustáquio AS and McGlinchey RP: Advances in and applications of proteasome inhibitors. Curr Opin Chem Biol 12: 434-440, 2008

26. Razeghi P, Baskin KK, Sharma S, et al: Atrophy, hypertrophy, and hypoxemia induce transcriptional regulators of the ubiquitin proteasome system in the rat heart. Biochem Biophys Res Commun 342: 361-364, 2006.

27. Meiners S, Laule M, Rother W, et al: Ubiquitin-proteasome pathway as a new target for the prevention of restenosis. Circulation 105: 483-489, 2002.

28. Barringhaus KG and Matsumura ME: The proteasome inhibitor lactacystin attenuates growth and migration of vascular smooth muscle cells and limits the response to arterial injury. Exp Clin Cardiol 12: 119-124, 2007.

29. Sanchez-Ponce D, Tapia M, Muñoz A and Garrido JJ: New role of IKK alpha/beta phosphorylated I kappa B alpha in axon outgrowth and axon initial segment development. Mol Cell Neurosci 37: 832-844, 2008.

30. Farber HW and Loscalzo J: Pulmonary arterial hypertension. $\mathrm{N}$ Engl J Med 351: 1655-1665, 2004.

31. Kee K and Naughton MT: Heart failure and the lung. Circ J 74: 2507-2516, 2010.

32. Iyer SS, Co C and Rojas M: Mesenchymal stem cells and inflammatory lung diseases. Panminerva Med 51: 5-16, 2009.

33. Baber SR, Deng W, Master RG, et al: Intratracheal mesenchymal stem cell administration attenuates monocrotaline-induced pulmonary hypertension and endothelial dysfunction. Am J Physiol Heart Circ Physiol 292: H1120- H1128, 2007.

34. Patel KM, Crisostomo P, Lahm T, et al: Mesenchymal stem cells attenuate hypoxic pulmonary vasoconstriction by a paracrine mechanism. J Surg Res 143: 281-285, 2007.

35. Diller GP, van Eijl S, Okonko DO, et al: Circulating endothelial progenitor cells in patients with Eisenmenger syndrome and idiopathic pulmonary arterial hypertension. Circulation 117: 3020-3030, 2008.

36. Daroczi B, Kari G, Ren Q, Dicker AP and Rodeck U: Nuclear factor kappa B inhibitors alleviate and the proteasome inhibitor PS-341 exacerbates radiation toxicity in zebrafish embryos. Mol Cancer Ther 8: 2625-2634, 2009.

37. Zavrski I, Kleeberg L, Kaiser M, et al: Proteasome as an emerging therapeutic target in cancer. Curr Pharm Des 13: 471-485, 2007.

38. Erl W, Hansson GK, de Martin R, Draude G, Weber KS and Weber C: Nuclear factor-kappa B regulates induction of apoptosis and inhibitor of apoptosis protein-1 expression in vascular smooth muscle cells. Circ Res 84: 668-677, 1999.

39. Grassia G, Maddaluno M, Musilli C, et al: The I $\{$ kappa\}B kinase inhibitor nuclear factor- $\{$ kappa $\} \mathrm{B}$ essential modulator-binding domain peptide for inhibition of injury-induced neointimal formation. Arterioscler Thromb Vasc Biol 30: 2458-2466, 2010. 